\section{Frequency, sequence, and side of ovulation in women menstruating normally}

Ovulation in the primate is usually regarded as a consistently alternating process that occurs with equal frequency in the right and left ovaries. We investigated whether ovulation in women occurs with equal frequency in each ovary, alternating consistently between the ovaries.

\section{Subjects, methods, and results}

Sixteen women ovulating normally who were awaiting donor insemination participated in the study. Pelvic ultrasonography was performed with a real time sector scanner (Advanced Diagnostic Research $4000 \mathrm{~S} / \mathrm{L}$ ) at least once during each cycle as close as possible to the day when basal body temperature was lowest. Ovulation was confirmed by records of biphasic basal body temperature, mean duration of luteal phase of 14 (SEM 2) days, and a mid-luteal plasma progesterone concentration $\geqslant 38.4 \mathrm{nmol} / \mathrm{l}(12 \mathrm{ng} / \mathrm{ml})$. Statistical analysis was based on the Bernolli distribution, assuming that in normal circumstances there is a $50 \%$ chance of ovulation occurring in either ovary.

A total of 97 follicles was observed in 16 women during 90 cycles. In seven cycles $(8 \%)$ two follicles were observed, always in the same ovary. Of the 97 follicles, $62(64 \%)$ were detected in the right and $35(36 \%)$ in the left ovary $(p<0 \cdot 01)$ (table). Alternation of side of ovulation in at least four consecutive

\begin{tabular}{lr}
$\begin{array}{l}\text { Sequence and side of ovulation in } 16 \text { women menstruating } \\
\text { normally }\end{array}$ \\
\hline No of cycles (No of women) & $90(16)$ \\
No of follicles & \\
Right ovary $(\%)$ & 97 \\
Left ovary (\%) & $62(64)$ \\
Alternate ovulationst: & $35(36)$ \\
No (\%) of women & \\
No $(\%)$ of cycles & $5(31)$ \\
Unilateral ovulationst: & $22(24)$ \\
No $(\%)$ of women & \\
No $(\%)$ of cycles & $4(25)$ \\
\end{tabular}

$\star$ Difference between left and right: $\mathrm{p}<0.01$

fObserved in at least four consecutive cycles.

cycles was found in five women (31\%) and in $22(24 \%)$ cycles. In four women ovulation was consistently unilateral from the right ovary during four to six cycles. In cycles with ipsilateral ovulation the mean follicular phase length was $15 \cdot 2(0.3)$ days. When ovulation occurred in the ovary contralateral to that which ovulated in the previous cycle the mean follicular phase was $14 \cdot 2(0 \cdot 3)$ days $(\mathrm{p}<0 \cdot 05)$.

\section{Comment}

These findings indicate that ovulation in women tends to occur more frequently in the right ovary and that the side of ovulation is closely related to the length of the follicular phase, probably being influenced by residual corpus luteum activity of the previous cycle. ${ }^{1}$

In a study of eight rhesus monkeys fresh corpus luteum was located in the right ovary in 52 of $86(60 \%)$ laparotomies. ${ }^{2}$ In our study ovulation occurred significantly more frequently in the right ovary (65\%). Furthermore, all four series of consecutive unilateral ovulations occurred in the right ovary. This predominance might be genetically determined or result from a difference in ovarian response to extragonadal stimulations owing to differences in vasculature of the ovaries. ${ }^{23}$

We observed alternation of ovulation in five women (31\%) and in no more than $24 \%$ of cycles. Marinho et al examined 15 healthy women and showed alternation of ovulation in $80 \%$ of 62 cycles. ${ }^{4}$ Thirteen of their patients, however, were followed for only four cycles, whereas in our study 10 out of 16 women were observed for six or more consecutive cycles. Moreover, in the Marinho study, no information was given about the three women who did not ovulate from alternate ovaries. In our study ipsilateral ovulation was observed in four women and all of them ovulated from the right ovary, supporting the theory that the right ovary is predominantly the site of ovulation.

Our study also indicates that in women the ovary in which ovulation will occur, as well as the length of follicular phase, may be influenced by the residual corpus luteum activity of the previous cycle. Thus in cycles with a follicular phase of 14 days or less the ovary seems still to be "suppressed" by the activity of the previous cycle, and therefore ovulation tends to occur on the other side. ${ }^{1}$ When the follicular phase is prolonged, on the other hand, the ovary may have sufficient time to free itself from this inhibitory effect, allowing ovulation to occur on the same side.

1 Wallach EE, Virutamasen $\mathrm{P}$, Wright $\mathrm{KH}$. Menstrual cycle characteristics and side of ovulation in the rhesus monkey. Ferril Steril 1973;24:715-21.

2 Morse AH, Van Wagenen G. Observations upon ovulation in primates Am $\mathcal{J}$ Obstet Gynecol 1936;32:823-32.

3 Beyth Y, Winston RML. Ovum capture and fertility following microsurgical fimbriectomy in the rabbit. Fertil Steril 1982;35:464-7.

4 Marinho AO, Sallam HN, Goessens L, Colling WP, Campbell S. Ovulation side and occurrence of mittelschmerz in spontaneous and induced ovarian cycles. BrMed I 1982:284:632.

(Accepted 1 October 1986)

Fertility Clinic, Division of Obstetrics and Gynaecology, Soroka Medical Center, PO Box 151, Beer Sheba 84 101, Israel

G POTASHNIK, MD, senior lecturer

V INSLER, MD, professor

I MEIZNER, MD, instructor

Department of Economics, Soroka University Hospital, Faculty of Health Sciences, Ben Gurion University of the Negev, Beer Sheba, Israel

M STERNBERG, PHD, lecturer

Correspondence to: Dr Potashnik.

\section{Depression and outcome in acute myocardial infarction}

A study was performed to assess the level of depression in the first 24 hours after acute myocardial infarction using the Montgomery-Asberg rating scale. ${ }^{1}$ The relation between depression and the eventual outcome in terms of both morbidity and reinfarction or myocardial arrest was also assessed.

\section{Patients, methods, and results}

A total of 108 patients admitted consecutively with a diagnosis of myocardial infarction was studied. The age and sex of the patient, the site and size of infarction, and the presence of left ventricular failure were noted. The patient's degree of depression was assessed with the Montgomery-Asberg rating scale between two and 24 hours after admission. Patients were classified as depressed if they scored 14 or more on the scale. The degree of pain suffered by the patient at the time of interview was also rated on a scale of $0-3,0$ representing no pain and 3 severe pain.

Of the 108 patients (age range 39-86, mean 62.9 years), 81 were men and 27 women. Infarct size, as measured by cardiac enzyme activities, showed no appreciable differences between patients who were and were not depressed: in those who were depressed aspartate transaminase activity was 210 (SD 167) IU/l (normal range 7-40 IU/1), and lactate dehydrogenase activity 615 (464) IU/1 (normal range 100-275 IU/l); in the patients who were not depressed aspartate transaminase activity was 202 (378) IU/I and lactate dehydrogenase activity 467 (337) IU/1. There were also no important differences between the two groups of patients in terms of site of infarction, pain suffered, and presence of left ventricular failure.

Forty eight patients scored 14 or more on the Montgomery-Asberg rating scale; of these, eight men died. Six patients (five men, one woman) suffered either myocardial arrest with successful resuscitation or further myocardial infarction. Of the 60 patients who were not depressed ( 46 men, 14 women), one man died and one woman suffered a further myocardial infarction.

Patients were classified into two groups: those with a poor outcome, who died or had a myocardial arrest or a further infarction, and those who survived without any of these complications. A $\chi^{2}$ analysis using Yates's correction for small numbers $\left(\chi^{2}=12 \cdot 2, n=105, p<0.001\right)$ showed the differences between the patients who were depressed and those who were not to be highly significant (table).

\section{Comment}

It has been observed that patients who become depressed do poorly. Such observations have been based on only a few patients with obvious severe depression. Studies using psychiatric rating scales have only recently been carried out and have shown a great deal of often unrecognised psychiatric 
morbidity in patients with acute medical conditions. ${ }^{2-4}$ Patients with psychiatric morbidity have a poorer outcome in terms of social adaptability and also further mortality and morbidity. ${ }^{5}$

The ratio of men to women in this study was 3:1, with $29 \%$ (14/48) of the patients with depression and $23 \%(14 / 60)$ of those without depression being women. Strikingly, 14 of the 16 patients who had a poor outcome were men $(\mathrm{p}<0.001)$.

\begin{tabular}{|c|c|c|c|}
\hline \multirow[b]{2}{*}{ Outcome } & \multicolumn{2}{|c|}{ Score on rating scale } & \multirow[b]{2}{*}{ Total } \\
\hline & $<14$ & $\geqslant 14$ & \\
\hline $\begin{array}{l}\text { Good } \\
\text { Poor }\end{array}$ & $\begin{array}{r}58 \\
2\end{array}$ & $\begin{array}{l}34 \\
14\end{array}$ & $\begin{array}{l}92 \\
16\end{array}$ \\
\hline Total & 60 & 48 & 108 \\
\hline
\end{tabular}

Clearly, depression in men in the first 24 hours after myocardial infarction represents a considerably increased risk of early death, reinfarction, or myocardial arrest, and therefore these patients should be closely monitored for longer than is at present routine.

I thank Dr J P H Davies, consultant cardiologist, for his support and encouragement in this study and $\operatorname{Dr} E M$ Phillips and Dr P Jenkins for allowing me to use their patients.

1 Montgomery SA, Asberg M. A new depression rating scale designed to be sensitive to change. Brf Psychiatry 1979;134:382.

2 Moffic HS, Paykel ES. Depression in medical inpatients. Brf Psychiatry 1975;126:346-53.

3 Anonymous. Psychiatric illness among medical patients [Editorial]. Lancet 1979;i:478-9.

4 Nabarro J. Unrecognised psychiatric illness in medical patients. Br Med f 1984;289:635-6.

5 Hawton $\mathrm{K}$. The long term outcome of psychiatric morbidity detected in general medical patients.

f Psychosom Res 1981;25:237-43.

(Accepted 6 October 1986)

Medical Unit, East Surrey Hospital, Redhill, Surrey

PETER H SILVERSTONE, MB, BS, medical registrar

Correspondence to: Maudsley Hospital, De Crepsigny Park, London SE5 8AZ.

\section{Henoch-Schönlein purpura associated with legionnaires' disease}

Legionnaires' disease, which classically presents as an atypical pneumonia, ${ }^{1}$ has occasionally been associated with cutaneous complications..$^{2.5}$ We report a case in which the presenting features were those of Henoch Schönlein purpura, for which no other cause was found.

\section{Case report}

A 43 year old homosexual man was admitted with a 10 day history of malaise, fever, dry cough, and arthralgia and a four day history of an eruption on the buttocks, legs, and extensor surfaces of the arms. Indomethacin had been prescribed by his general practitioner for symptomatic relief after the rash developed, and he was not receiving any other drugs. Three days before admission he developed colicky abdominal pain associated with the passage of bright red blood per rectum. Direct questioning elicited that he had contracted yellow fever, malaria, hepatitis, and amoebic dysentery while on a visit to Nigeria 21 years previously and had been treated for gonorrhoea nine months previously.

On examination he was febrile (temperature $38.2^{\circ} \mathrm{C}$ ), with reduced breath sounds, dullness to percussion, and crepitations at the left base of the lung. There was mild tenderness of the abdomen, and rectal examination gave normal results. The results of cardiovascular and neurological examinations were also normal. He had a widespread maculopapular purpuric eruption scattered over the legs and buttocks typical of Henoch Schönlein purpura (figure). Haematological investigation showed a normal haemoglobin concentration with a leucocytosis of $13 \cdot 1 \times$ $10^{9} / 1$ (neutrophils $11.2 \times 10^{9} / 1$, lymphocytes $1.2 \times 10^{9} / 1$, monocytes $0.6 \times 10^{9} /$ ); a platelet count of $380 \times 10^{9} /$; an erythrocyte sedimentation rate of $34 \mathrm{~mm}$ in the first hour; a British clotting ratio of $1 \cdot 1$; a negative result to a Paul-Bunnell test, and no cryoglobulins or cold agglutinins. Electrolyte, urea, serum urate 00 immunoglobulin, and complement concentrations were normal, as were rena $\Gamma$ clearance of edetic acid and results of liver function tests. Blood cultures, sputum culture, and midstream specimen of urine produced no growth, and there was no proteinuria or microscopic haematuria. A chest $x$ ray film showed shadowing at the left base.

Treatment was started as for an atypical pneumonia with intravenouserythromycin, and this led to rapid resolution of the chest signs and the rash. The following were found subsequently to be negative or normal: antistreptolysin $\phi_{D}$ titre; results of the Venereal Disease Research Laboratory test and Treponemos pallidum haemagglutination assay; hepatitis B surface antigen; antinuclear factofT and autoantibody screen; and titres of antibodies to Mycoplasma pneumoniae? yersinia, Chlamydia psittaci and Coxiella burnetii. Legionella pneumophila antibody titres, by contrast, rose from $1 / 16$ on admission to $1 / 64$ five days later, as measureds by both the rapid microagglutination test and the immunofluorescence antibody test, which is diagnostic of legionnaires' disease (Public Health Laboratory). In'

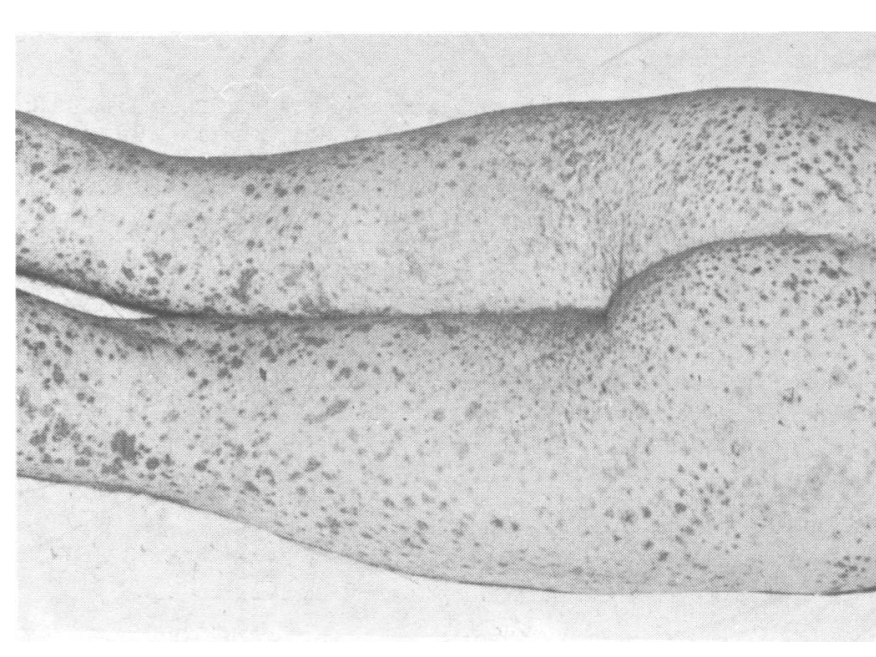

Purpuric eruption on buttocks and legs.

view of the patient's social history skin biopsy was postponed pending the resulpo of a test to determine whether he was positive or negative for antibody to human immunodeficiency virus. By the time we knew that he was negative the skin eruption had faded, so that a specimen could not be obtained for histopathologica尽 examination.

\section{Comment}

There have been only four previous reports of a cutaneous eruption associated with legionnaires' disease; these eruptions have included throm botic thrombocytopenic purpura, ${ }^{23}$ disseminated intravascular coagula tion, ${ }^{34}$ and erythema multiforme. ${ }^{5}$ To our knowledge this is the first recorded case of Henoch Schönlein purpura associated with legionnaires disease.

1 Beaty HN Clinical features of legionnellosis. In: Thornsberry C, Balows A, Feeley JC, Jakubowsk W. Legionella. Proceedings of the 2nd international symposium. Washington, DC: American SocietiO W. Legionella. Proceedings of

2 Gasper TM, Farndon PA, Davies R. Thrombocytopenia associated with legionnaires' disease BrMed f 1978;ii:1611-2.

3 Riggs SA, Wray NP, Waddell CC, Rossen RD, Gyorkey F. Thrombotic thrombocytopeniq purpura complicating legionnaires' disease. Arch Intern Med 1982;142:2275-80.

4 Oldenburger D, Carson JP, Gundlach WJ, Ghaly FI, Wright WH. Legionnaires' disease. Association with Mycoplasma pneumonia and disseminated intravascular coagulation. $\mathcal{F A M} F$ 1979;241:1269-70.

5 Andersen R, Bergan T, Halvorsen K, Kallings I, Orstavik I. Legionnaires' disease combined with erythema multiforme in a 3-year-old boy. Acta Paediatr Scand 1981;70:427-31.

(Accepted 21 October 1986)

\section{Charing Cross Hospital, London W6 8RF}

P W BULL, MRCP, senior registrar, department of rheumatology

J T SCOTT, MD, FRCP, consultant physician, department of rheumatology

$S$ M BREATHNACH, MD, MRCP, senior lecturer and honorarv consultant department of medicine (dermatology)

Correspondence to: Dr Breathnach. (1) 